Topical Review

\title{
Hormonal, Electrolytic, and Electrocardiographic Evaluations in Bitches With Eutocia and Dystocia
}

\author{
Carla Regina Barbieri Simões, DVM, MSc a , Flávia Gardilin Vassalo, DVM, MSc ${ }^{\text {, }}$ \\ Maria Lúcia Gomes Lourenço, DVM, MSc, PhD ${ }^{\mathrm{b}}$, Fabiana Ferreira de Souza, DVM, MSc, PhD ${ }^{\mathrm{a}, *}$, \\ Eunice Oba, DVM, MSc, PhD ${ }^{\mathrm{a}}$, Mateus José Sudano, DVM, MSc, PhD ${ }^{\mathrm{a}, 1}$, \\ Nereu Carlos Prestes, DVM, MSc, PhD ${ }^{\mathrm{a}}$
}

\author{
Keywords: \\ birth \\ delivery \\ dog \\ hormone \\ pregnancy \\ ${ }^{a}$ Department of Animal Reproduction, \\ Universidade Estadual Paulista, UNESP, \\ Botucatu, Sao Paulo, Brazil \\ ${ }^{b}$ Department of Medical Clinic, Universidade \\ Estadual Paulista, UNESP, Botucatu, Sao Paulo, \\ Brazil \\ *Address reprint requests to Fabiana \\ Ferreira de Souza, DVM, MSc, PhD, \\ Departamento de Reprodução Animal, \\ FMVZ, Universidade Estadual Paulista \\ (UNESP), Distrito de Rubião Junior, s/n, CEP \\ 18.618-970, Botucatu, Sao Paulo, Brazil. \\ E-mail: fafesouza@fmvz.unesp.br \\ (F.F. de Souza)
}

\begin{abstract}
The objective of the study was to assess clinical alterations, electrocardiographic, hematological, biochemical, hemogasometric, electrolytic, and hormone plasma concentrations in bitches with eutocia and dystocia. Overall, 28 bitches (dystocia, $n=22$ and eutocia, $n=6$ ) were assessed. The evaluations were performed at 2 time points, M1 (1 hour prepartum-eutocia group and cesarean or clinical intervention-dystocia group) and M2 (postpartum-eutocia or dystocia group and anesthetic recoverydystocia group). The main clinical finding was the hypothermia (mean: $36.9^{\circ} \mathrm{C}$ dystocia vs. $36.8^{\circ} \mathrm{C}$ eutocia). Sinus arrhythmia and tachycardia were the electrocardiographic parameters predominant in eutocia and sinus rhythm in dystocia group. The $\mathrm{P}$ wave amplitude, heart rate, creatinine concentration, hematocrit, and hemoglobin were increased in M1 $(P<.05)$, whereas the concentration of $\mathrm{TCO}_{2}$ was higher in M2. There was an increase in $\mathrm{P}_{4}$ concentration in dystocia and total $\mathrm{T}_{3}$ concentrations were increased in $\mathrm{M} 1$ in both groups. Total $\mathrm{T}_{4}$ was higher in dystocia during $\mathrm{M} 1$ and in dystocia during $\mathrm{M} 2$ in eutocia than in dystocia. We concluded that at 1 hour prepartum or pre-cesarean, there is an increase in heart rate in bitches with eutocia or dystocia, and this finding was correlated to thyroid hormone concentration. $\mathrm{P}_{4}$ concentrations remained high during dystocia, and hematological and biochemical changes returned to normal after parturition. The evaluation of these parameters in pregnancy can be used as tool to prevent dystocia and consequent fetal death.
\end{abstract}

c 2016 Elsevier Inc. All rights reserved.

\section{Introduction}

Pregnancy involves hormonal changes and electrolyte and electrocardiographic changes, which can be physiological and related to eutocia or can predispose to dystocia. The endocrine mechanisms involved in pregnancy and parturition in bitches have not yet been fully elucidated.

The duration of pregnancy in dogs ranges from 56-68 days depending on the initial date considered. ${ }^{2}$ In general, it can be considered that parturition occurs 63 days after ovulation. The progesterone produced by the corpus luteum is responsible for the maintenance of pregnancy, and its secretion is dependent on the luteotrophic hormones and prolactin. ${ }^{3}$ Plasma progesterone secretions are less than $2 \mathrm{ng} / \mathrm{mL}$ between 36 and 48 hours before parturition. $^{4}$

Thyroid hormones have important functions during pregnancy and parturition, ${ }^{5}$ and their concentrations are involved in an increase in oxygen consumption, cholesterol excretion, glucose absorption, enhanced insulin action, increased force of cardiac contraction and heart rate (HR), an increase in stroke volume and intestinal peristalsis, and secretion of growth hormone in pregnant female dogs. ${ }^{6,7}$ In the fetus, thyroid hormones are important for development of the neural and skeletal systems.,

Cardiac arrhythmia is the main cardiovascular change observed during the last 40 days of gestation and in normal parturition, which shows the importance of understanding physiological events in bitches to identify cardiac abnormalities, ${ }^{10}$ especially during dystocia, which requires anesthesia and surgery.

Dystocia is the difficulty or the inability to expel a fetus through the birth canal, which may have maternal causes, fetal causes, or a combination of both. ${ }^{11}$ In bitches, dystocia is a common problem, although the changes related to cardiac function and electrolyte, biochemical, hormonal, and blood parameters during parturition are not fully known to establish an appropriate treatment. In view of this, the aim of this study was to describe hormones (progesterone, triiodothyronine, and thyroxine), electrolytes (ionized calcium, sodium, potassium chloride, and carbon dioxide), hematological changes (hematocrit, hemoglobin, urea, creatinine, and glucose), and electrocardiographic changes from bitches in eutocia and dystocia, during prodrome and postpartum.

\section{Materials and Methods}

da UNESP-Universidade Estadual Paulista).

1 Present address: School of Veterinary Medicine, Federal University of Pampa, BR 472, Km 585, PO Box 118, Zip Code 97.501-970, Uruguaiana, Rio Grande do Sul, Brazil.
The study was conducted in accordance with the ethical principles recommended by Science of the Brazilian Society of 
Laboratory Animals and the Brazilian College of Animal Experimentation (SBCLA/COBEA) and was approved by the Ethics Committee on Institutional Animal Use under protocol no. 07/2012-CEUA.

Bitches of 28 different breeds (Poodle, Pinscher, Lhasa-Apso, Spitz, West Corgi, Shih Tzu, Samoyed, and crossbreed), nulliparous or pluriparous, aged between 2 and 5 years and weighing between 2 and $24 \mathrm{~kg}$ were used. The bitches were separated into 2 groups, a dystocia group ( $n=22)$ and eutocia group $(n=6)$. The criterion to form the groups were the owner did not provide medication during pregnancy or parturition, unless the team's has indicated.

All female dogs of eutocia group were evaluated by ultrasound approximately 25 days after mating to diagnose pregnancy. The pregnant bitches were monitored weekly to assess the clinical and behavioral parameters (data not shown). In the last week of pregnancy ( $\sim 57$ days), the bitches were evaluated every other day, by clinical, behavioral, and ultrasound examination to check the fetal viability (data not shown). In addition, the owners were contacted daily by phone to ask about behavior change (anxiety, apprehension, appetite reduction, nesting behavior, seek seclusion, and gasping). Onset of parturition was stablised with the reduction or absence of appetite, nesting behavior, rectal temperature decline, shivering, apprehension, seek seclusion, gasping and lochial vulvar greenish black discharge, associated with abdominal straining. The bitches of this group were followed in the owner's home during parturition without any obstetrical intervention. Eutocia group was composed by bitches demonstrating abdominal straining, fetal expulsion and interval between the puppies birth $<120$ minutes. Fetal expulsion was followed by abdominal palpation of the uterus to confirm presence or absence of the fetus.

The bitches of the dystocia group were selected from care unit of veterinary hospital based on an absence of abdominal contractions, clear signs of an expulsion phase and rupture of fetal membranes without expulsion of the fetus, fetal dystocia, fetal distress (heart rate $<150 \mathrm{bpm}$ in ultrasound examination), or fetal maceration or all of these, and a maximum interval of 12-16 hours between the birth of the last fetus until diagnosis. In all female dogs from this group, the treatment was cesarean section. Fetal distress was considered, when the HR of the puppies in ultrasound examination was less than $150 \mathrm{bpm} .^{4}$

Analyses were performed at 2 time points, M1-approximately 1 hour before parturition (gasping and abdominal straining) in the eutocia group and 1 hour before cesarean section in the dystocia group, and M2-1 hour postexpulsion of all fetuses and 1 hour postanesthetic recovery in bitches of the eutocia and dystocia group, respectively.

For cesarean section, bitches were anesthetized with propofol intravenously to induce loss of the laryngotracheal reflex. Epidural infusion ( $1.0 \mathrm{~mL} / 5 \mathrm{~kg} 2 \%$ lidocaine with $0.1 \mathrm{mg} / \mathrm{kg}$ morphine) was performed, and anesthesia was maintained with isoflurane diluted in $100 \%$ oxygen in a valve circle anesthetic circuit.

The electrocardiographic pattern was monitored with standard bipolar leads using the frontal plane, with conscious dogs being placed in right lateral recumbency and with the fore and hind limbs placed at right angles to the long axis of the body. The electrodes were attached to the forelegs (in the anterolateral skin fold situated immediately above the olecranon process; a red electrode was placed on the right leg and a yellow electrode was placed on the left leg) and the hind legs (in the skin fold at knee level; a green electrode on the left leg and a black electrode on the right leg). ${ }^{12}$ The recording was performed using a 12-channel electrocardiograph (ECG module on the Computer Module ECG-PC TEB; Tecnologia Eletrônica Brasileira, São Paulo, Brazil), which was directly connected to an automatic microcomputer. A $50 \mathrm{~mm} / \mathrm{s}$ paper speed was used, with a calibration of $10 \mathrm{~mm} / \mathrm{mV}(1 \mathrm{mv}=$ $1 \mathrm{~cm}$ ). All readings were obtained simultaneously to reduce the length of time that the dogs were restrained. The following parameters were analyzed in all leads: $\mathrm{P}$ and $\mathrm{T}$ waves; QRS complex; and the PR, QT, and RR intervals to measure amplitude (mv) and duration (seconds). The morphology, HR, cardiac rhythms, and polarity of the $\mathrm{T}$ wave were assessed. The mean electrical axis was calculated by using leads I and III, based on the method described by Tilley. ${ }^{12}$

After cardiac evaluation, the bitches were kept in lateral recumbency and blood samples were collected from the jugular vein. An aliquot $(2.5 \mu \mathrm{L})$ was used to determine hematological (Hct = hematocrit [\%] and $\mathrm{Hb}=$ hemoglobin $[\mathrm{g} / \mathrm{dL}]$ ), biochemical (Gluc $=$ glucose $[\mathrm{mg} / \mathrm{dL}]$, urea $[\mathrm{mg} / \mathrm{dL}]$, and Creat $=$ creatinine $[\mathrm{mg} / \mathrm{dL}]$ ), hemogasometric (serum total carbon dioxide $\left[\mathrm{TCO}_{2}\right.$, $\mathrm{mmol} / \mathrm{L}]$ ) and electrolytic parameters (sodium $\left[\mathrm{Na}^{+}, \mathrm{mmol} / \mathrm{L}\right]$, potassium $\left[\mathrm{K}^{+}, \mathrm{mmol} / \mathrm{L}\right]$, chloride $\left[\mathrm{Cl}^{-}, \mathrm{mEq} / \mathrm{L}\right]$, and ionized calcium [iCa, mmol/L]) in a portable analyzer (i-STAT ABBOTT, TX). The remainder of the blood was centrifuged $(1,000 \times g / 10$ minutes $)$ to obtain plasma.

The determination of hormone levels was performed by radioimmunoassay for progesterone $\left(\mathrm{P}_{4}\right.$, DPC-Diagnostic Products Corporation, Bergenfield, NJ), triiodothyronine (total $T_{3}$, DPCDiagnostic Products Corporation, Bergenfield, NJ), and thyroxine (total $\mathrm{T}_{4}$, DPC-Diagnostic Products Corporation, Bergenfield, NJ) at the endocrinology laboratory. The concentrations were determined by a gamma counter (Gamma Count, Perkin Elmer, Waltham, MA).

The dependent variables, with repeated measures on the time and clinical evaluation ( $T^{\circ} \mathrm{C}$ and $f$ ), cardiac (RR, Ps, RmV, Ts, PmV, $\mathrm{P}-\mathrm{R}, \mathrm{QRSs}$, and axis), hematological (Hct and $\mathrm{Hb}$ ), biochemical (Glic, urea, and Creat), hemogasometric $\left(\mathrm{TCO}_{2}\right)$ and electrolytic parameters $\left(\mathrm{Na}^{+}, \mathrm{K}^{+}, \mathrm{Cl}^{-}\right.$, and iCa), and hormone levels $\left(\mathrm{P}_{4}\right.$, total $T_{3}$, and total $T_{4}$ ) were analyzed by analysis of variance using the PROC MIXED of SAS (SAS Inst. Inc., Cary, NC). Sources of variation in the model included parturition (dystocia and eutocia), time (M1 and M2), and first order interactions; however, all effects were considered fixed effects. The animals were considered a random effect. When the probability of the difference between parturition, time, and first order interactions was significant, means were separated using the difference between the minimum frames. Data were presented as the means of least squares and standard errors. In the absence of significant interactions, only the main effects were presented. For all analyses, a significance level of 5\% was adopted.

\section{Results}

In dystocia group was predominant bitches weighing $<4 \mathrm{~kg}$ (46\%), followed by between 5 and $10 \mathrm{~kg}$ (27\%) and more than $10 \mathrm{~kg}$ (27\%), whereas the eutocia group prevailed both female dogs weighing between 5 and $10 \mathrm{~kg}$ or more than $10 \mathrm{~kg}$ (33\% both weights), followed by smaller bitches with $<4 \mathrm{~kg}$ (17\%).

Most female dogs with eutocia or dystocia were primiparous ( $50 \%$ in both groups), followed by the second parity (33\% and 32\%), and third or more parities (17\% and $18 \%$ ), respectively. Mean \pm standard error of litter size of eutocia (total 54 puppies) and dystocia group (total 33 puppies) was $5.50 \pm 0.72$ and $2.84 \pm$ 0.31 puppies, respectively. We recorded $9.1 \%$ (3/33) and $7.4 \%$ $(4 / 54)$ of stillborn, respectively, in eutocia and dystocia group, considering the total puppies born in each group.

Mean and standard error of clinical, electrocardiographic, hematological, biochemical, hemogasometric, electrolytic parameters, and hormonal concentrations were presented in Tables 1-4.

In the bitches with eutocia, we observed the same percentage of sinus arrhythmia and tachycardia in M1 (50.0\%), with a predominance of sinus arrhythmia in M2 (66.7\%). However, in 
Table 1

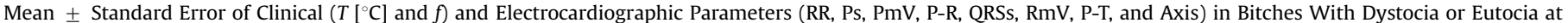
2 Time Points (M1 and M2)

\begin{tabular}{|c|c|c|c|c|c|c|}
\hline \multirow[t]{2}{*}{ Parameter } & \multicolumn{3}{|l|}{ Parturition Type } & \multicolumn{3}{|l|}{ Time Point } \\
\hline & Dystocia & Eutocia & $P^{*}$ & M1 & M2 & $P^{*}$ \\
\hline$T\left({ }^{\circ} \mathrm{C}\right)$ & $36.8 \pm 0.14$ & $36.8 \pm 0.27$ & 0.79 & $36.8 \pm 0.20$ & $36.8 \pm 0.20$ & 0.86 \\
\hline$f(\mathrm{bpm})$ & $53.4 \pm 3.0$ & $59.9 \pm 5.8$ & 0.33 & $60.8 \pm 4.7$ & $52.5 \pm 4.7$ & 0.22 \\
\hline $\mathrm{RR}$ (bpm) & $150.6 \pm 4.1$ & $170.5 \pm 7.7$ & 0.03 & $166.8 \pm 5.1$ & $154.3 \pm 5.1$ & 0.02 \\
\hline Ps (seg) & $0.041 \pm 0.001$ & $0.038 \pm 0.003$ & 0.36 & $0.042 \pm 0.002$ & $0.037 \pm 0.002$ & 0.23 \\
\hline $\mathrm{RmV}(\mathrm{mV})$ & $0.981 \pm 0.05$ & $0.910 \pm 0.11$ & 0.57 & $0.932 \pm 0.07$ & $0.960 \pm 0.07$ & 0.59 \\
\hline Ts (seg) & $0.050 \pm 0.003$ & $0.052 \pm 0.007$ & 0.83 & $0.052 \pm 0.004$ & $0.051 \pm 0.004$ & 0.89 \\
\hline $\operatorname{PmV}(\mathrm{mV})$ & $0.225 \pm 0.01$ & $0.213 \pm 0.02$ & 0.68 & $0.246 \pm 0.01 a$ & $0.192 \pm 0.01 \mathrm{~b}$ & 0.03 \\
\hline $\mathrm{P}-\mathrm{R}(\mathrm{s})$ & $0.073 \pm 0.003$ & $0.067 \pm 0.006$ & 0.40 & $0.073 \pm 0.004$ & $0.067 \pm 0.004$ & 0.27 \\
\hline QRSs (s) & $0.070 \pm 0.01$ & $0.050 \pm 0.02$ & 0.42 & $0.066 \pm 0.01$ & $0.054 \pm 0.01$ & 0.64 \\
\hline Axis (deg.) & $54.1 \pm 4.3$ & $54.2 \pm 8.3$ & 0.99 & $52.2 \pm 4.9$ & $56.0 \pm 4.9$ & 0.18 \\
\hline
\end{tabular}

* Significant difference $P<.05$.

dogs with dystocia, sinus rhythm was predominant in both time points ( $\mathrm{M} 1=45.5 \%$ and $\mathrm{M} 2=59.1 \%$ ).

All bitches had decreased hemoglobin concentrations and hematocrit percentages in both time points (Table 2), considering the normal values of the species. The serum creatinine concentrations were within the normal range of the species.

\section{Discussion}

Dystocia was prevalent in miniature and small breeds, as described by Münnich and Küchenmeister. ${ }^{13}$ The association between primiparous and small breeds may have contributed to dystocia, as this group was composed specially by small breeds and $50 \%$ primiparous. Despite this, the female dogs were younger, in which the dystocia incidence is smaller than the primaparous of older age. ${ }^{13}$ Moreover, around $50 \%$ of bitches of eutocia group were also primiparous, though the most were large breeds. Litter size was lower in dystocia group, probably because it was composed for most of miniature and small breeds.

Single pup syndrome is considered one of main factors that inhibit the onset of parturition in bitches, which is more common in older dogs. ${ }^{14}$ In this syndrome, the parturition is not started owing to lack of adequate stimulus promoted by the release of fetal cortisol, resulting in failure of luteolysis. ${ }^{15}$ In this study, we did not verify the syndrome, although the smaller litter size were more frequent in dystocia group and all bitches started the parturition, even those with only single fetus $(n=4)$. However, the female dogs of this group (dystocia) were young and from small breeds, which justifies a smaller litter size.

The increased HR during parturition in the eutocia group has been mentioned by Gabas et al. ${ }^{16}$ In our study, the HR values in eutocia or dystocia were above the normal range for the species. These results can be explained by adaptive changes during pregnancy in the cardiovascular system, increased uterine perfusion, and increased cardiac output and blood volume, which are related to the synthesis and secretion of thyroid hormones. ${ }^{17}$ Moreover, failure of maternal cardiovascular adaptation during pregnancy may promote an increase in cardiac output and decreased fetal perfusion. ${ }^{18}$ In pregnant bitches with systemic diseases, decreased HR predisposes to abortion or perinatal death. ${ }^{19}$ However, in bitches undergoing cesarean section in the dystocia group, decreasing HR was associated with anesthesia in M2, in accordance with Fantoni et al. ${ }^{20}$ The increased HR in the eutocia group can be explained by the parturition stage because the bitches in the eutocia group were in stage II (fetal expulsion), whereas the dystocia bitches had not reached stage II or had already passed this stage.

According to our knowledge, there is no information concerning the alterations of $\mathrm{P}$ wave amplitude during the pregnancy or parturition of bitches. Nevertheless, the higher P wave amplitude in M1 found in our study can be related to right atrial enlargement, caused by dilation or hypertrophy, wherein there is a longer distance for the pulse to travel between the sinus and atrioventricular node. ${ }^{21}$ In contrast, Blanco and Batista ${ }^{10}$ reported a decrease in the amplitude of the $\mathrm{P}$ wave in pregnant bitches or in dystocia that correlated with electrolytic changes from pregnancy.

The predominant rhythm was sinus arrhythmia in the eutocia group and sinus rhythm in the dystocia group, which is in disagreement with Lucio $^{22}$ that he observed sinus arrhythmia in both groups. Sinus arrhythmia in the electrocardiographic tracing is considered physiologic. During inspiration there is decreased

Table 2

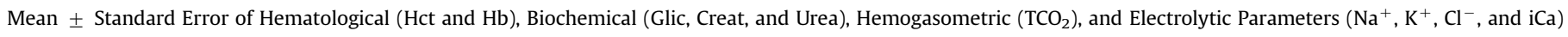

\begin{tabular}{|c|c|c|c|c|c|c|}
\hline \multirow[t]{2}{*}{ Parameter } & \multicolumn{3}{|c|}{ Parturition Type } & \multicolumn{3}{|l|}{ Moment } \\
\hline & Dystocia & Eutocia & $P^{*}$ & M1 & M2 & $P^{*}$ \\
\hline Hct (\%) & $28.1 \pm 0.9$ & $33.8 \pm 1.8$ & 0.01 & $33.9 \pm 1.3$ & $28.0 \pm 1.3$ & 0.001 \\
\hline $\mathrm{Hb}(\mu \mathrm{g} / \mathrm{dL})$ & $9.8 \pm 0.3$ & $11.5 \pm 0.5$ & 0.01 & $11.5 \pm 0.3$ & $9.7 \pm 0.3$ & 0.0002 \\
\hline Glic (mg/dL) & $125.0 \pm 7.5$ & $104.9 \pm 14.4$ & 0.22 & $109.8 \pm 10.7$ & $120.1 \pm 10.7$ & 0.46 \\
\hline Urea (mg/dL) & $16.9 \pm 1.9$ & $14.6 \pm 3.7$ & 0.58 & $15.5 \pm 2.1$ & $16.0 \pm 2.1$ & 0.52 \\
\hline Creat (mg/dL) & $0.54 \pm 0.05$ & $0.77 \pm 0.09$ & 0.04 & $0.77 \pm 0.06$ & $0.55 \pm 0.06$ & 0.01 \\
\hline $\mathrm{TCO}_{2}(\mathrm{mMol} / \mathrm{L})$ & $18.8 \pm 0.4$ & $18.0 \pm 0.5$ & 0.41 & $17.8 \pm 0.7$ & $19.0 \pm 0.7$ & 0.05 \\
\hline $\mathrm{Na}^{+}(\mathrm{mMol} / \mathrm{L})$ & $142.3 \pm 0.7$ & $144.8 \pm 1.4$ & 0.15 & $143.9 \pm 0.8$ & $143.2 \pm 0.8$ & 0.27 \\
\hline $\mathrm{K}^{+}(\mathrm{mMol} / \mathrm{L})$ & $3.9 \pm 0.1$ & $3.8 \pm 0.1$ & 0.90 & $3.9 \pm 0.1$ & $3.8 \pm 0.1$ & 0.24 \\
\hline $\mathrm{Cl}^{-}(\mathrm{mEq} / \mathrm{L})$ & $114.8 \pm 0.8$ & $116.6 \pm 1.6$ & 0.31 & $115.9 \pm 0.9$ & $115.5 \pm 0.9$ & 0.62 \\
\hline iCa $(\mathrm{mMol} / \mathrm{L})$ & $3.9 \pm 0.16$ & $4.4 \pm 0.31$ & 0.12 & $4.1 \pm 0.2$ & $4.2 \pm 0.2$ & 0.66 \\
\hline
\end{tabular}

\footnotetext{
* Significant difference $P<.05$.
} 
Table 3

Mean \pm Standard Error of Total $\mathrm{T}_{3}$ and $\mathrm{P}_{4}$

\begin{tabular}{|c|c|c|c|c|c|c|}
\hline \multirow[t]{2}{*}{ Parameter } & \multicolumn{3}{|c|}{ Parturition Type } & \multicolumn{3}{|l|}{ Time Point } \\
\hline & Dystocia & Eutocia & $P^{*}$ & M1 & M2 & $P^{*}$ \\
\hline Total $\mathrm{T}_{3}(\mathrm{ng} / \mathrm{dL})$ & $82.7 \pm 5.0$ & $88.7 \pm 9.6$ & 0.58 & $95.1 \pm 6.1$ & $76.3 \pm 6.0$ & 0.001 \\
\hline $\mathrm{P}_{4}(\mathrm{ng} / \mathrm{mL})$ & $11.6 \pm 0.5$ & $6.4 \pm 1.0$ & 0.0005 & $9.5 \pm 0.8$ & $8.5 \pm 0.8$ & 0.38 \\
\hline
\end{tabular}

* Significant difference $P<.05$.

vagal tone, which results in a reduction of the P-P interval, whereas during expiration there is an extension of this interval. ${ }^{23}$ During pregnancy, the increase in uterine volume promotes the reduction of lung expansion, resulting in compensatory tachypnea owing to a smaller area of pulmonary exchange. This physiological mechanism favors the emergence of the arrhythmias observed in our study.

In both groups, the bitches had a relatively decreased hemoglobin concentration (hemoglobin: $10-11 \mathrm{~g} / \mathrm{dL}$ ) or mild anemia (hemoglobin: 8-10 g/dL) ${ }^{24}$ with a low hematocrit (between $29 \%$ and $35 \%$ ), which is compatible with the anemic profile described during pregnancy in these species. ${ }^{3}$ Nevertheless, the hematocrit percentage and hemoglobin concentration were higher in the group dystocia, which has not been described by other authors. Only Chaudhari and Mshelia ${ }^{25}$ described hemoglobin concentrations in bitches at some stages of the estrous cycle, including pregnancy, but found no significant difference. The hematological alterations found in our study suggest hemodilution owing to increased blood volume, which accompanies the increased weight gain (20\%-55\% weight gain) during pregnancy. ${ }^{26}$ Regarding the differences between time points, in M1 these parameters were higher, which can be explained by the relationship between the reduction of blood flow and the rapid uterine involution immediately after birth. ${ }^{27}$

Although serum creatinine values varied between groups and time points, the observed concentrations were within the normal range for the species, ${ }^{28}$ and the findings can be justified by parturition, which predisposes to biochemical changes in view of the stress caused by pain (uterine and abdominal contractions), fetal corticosteroid secretions, and the lower circulating blood volume, which was transferred to the uterine compartment. ${ }^{26}$

The electrolytic variables were not influenced by the parturition type or time point evaluated, but $\mathrm{TCO}_{2}$ concentrations were higher in $\mathrm{M} 2$ in both groups. These findings are contrary to those observed by Gabas et al, ${ }^{16}$ which found no increase in $\mathrm{TCO}_{2}$ in bitches postcesarean section. Our findings were expected owing to decreasing arterial blood $\mathrm{pH}$ and decreased respiratory rate during pregnancy. Additionally, during pregnancy significant physiological changes occur in respiratory function, predisposing the bitch to an increased sensitivity of the respiratory center to the partial pressure of arterial blood $\mathrm{TCO}_{2}{ }^{29}$

Regarding hormonal concentrations, increased fetal cortisol predisposes to increased maternal cortisol, leading to the con-

Table 4

Mean \pm Standard Error of Total $\mathrm{T}_{4}(\mu \mathrm{g} / \mathrm{dL})$

\begin{tabular}{lll}
\hline Parturition Type & \multicolumn{2}{l}{ Time Point } \\
\cline { 2 - 3 } & M1 & M2 \\
\hline Dystocia & $4.6 \pm 0.3^{\mathrm{aA}}$ & $3.7 \pm 0.3^{\mathrm{bB}}$ \\
Eutocia & $4.0 \pm 0.6^{\mathrm{aA}}$ & $5.2 \pm 0.6^{\mathrm{aB}}$ \\
\hline
\end{tabular}

Different lower case letters $\left({ }^{\mathrm{a}, \mathrm{b}}\right)$ in the same row (M1 versus $\mathrm{M} 2$ ) and upper case letters $\left({ }^{A}, \mathrm{~B}\right)$ in the same column (Dystocia versus Eutocia) indicate a significant difference $(P<0.05)$ version of progesterone into estrogens. Estrogen is involved in prostaglandin synthesis, which induces myometrial contraction. In dystocia, the increase of progesterone is related to fetal death, which can interfere with prostaglandin synthesis, justifying dystocia. ${ }^{30}$ In our study, we did not assess prostaglandin metabolites and estrogen concentrations, but a higher progesterone concentration was observed in bitches that had cesarean section, which could be the reason for dystocia, ${ }^{31}$ although the primary inertia can occur without failure of luteolysis. ${ }^{32}$

We found increased total $T_{3}$ in $M 1$ in bitches with eutocia or dystocia and increased total $\mathrm{T}_{4}$ concentrations in the dystocia group, which have been described in women before parturition. ${ }^{33}$ Higher concentrations of both total $\mathrm{T}_{3}$ and $\mathrm{T}_{4}$ during normal pregnancies were associated with increased thyroglobulin induced by increased estrogen levels. ${ }^{34}$ Thus, in dystocia, it is possible that there was an increase in estrogen concentrations; however, the concentrations were not sufficient to complete the delivery. In dystocia group, relationship between the parturition difficulty and changes in thyroid hormones could be associated with the euthyroid sick syndrome, or the use of some drugs. Furthermore, diseases that can weaken the patient may lead to a decrease in circulating levels of thyroid hormones, without this being hypothyroidism (reviewed in Ref. 35). We can affirm that the female dogs in dystocia were not treated with drugs that alter the endocrine tests, as sulfa drugs, glucocorticoids, nonsteroidal antiinflammatory, clomipramine or phenobarbital. ${ }^{36}$ In addition, female dogs had no history of medical conditions during pregnancy.

We conclude that the prepartum increase in HR in bitches with eutocia or dystocia is correlated with fetal and maternal stress, which results from changes in thyroid hormones. In addition, higher concentrations of progesterone during parturition are directly involved in dystocia. The hematological and biochemical changes observed during pregnancy return to normal after delivery. Monitoring these and other cardiovascular parameters may be a complementary tool for the establishment of normal pregnancy and the prevention of dystocia. Furthermore, when bitches require cesarean section, it is important to know the physiological parameters of dystocia because there is a greater surgical or anesthetic risk during cesarean section.

\section{References}

1. Veiga GAL, Silva LCG, Lúcio CF, Rodrigues JA, Vannucchi CI. Endocrinology of pregnancy and parturition in bitches (Endocrinologia da gestação e parto nas cadelas). Rev Bras Reprod Anim 33:3-10, 2009

2. Kim MY, Travis AJ, Meyers-Wallen VN. Parturition prediction and time of canine pregnancy. Theriogenology 68:1177-1182, 2007

3. Concannon PW, Castracane VD, Temple M, Montanez A. Endocrine control of ovarian function in dogs and other carnivores. Anim Reprod Sci 6:172-193, 2009

4. Johnston SD, Kustritz MVR, Olson PNS. Canine pregnancy. In: Johnston SD, Kustritz MVR, Olson PNS, editors. Canine and Feline Theriogenology. Philadelphia: Saunders; 2001. p. 19-104

5. Galofré JC, Davies T. Thyroid dysfunction in pregnancy. Endocrinol Nutr 54:535-546, 2007

6. Guyton AC, Hall JE. Ação dos hormônios. In: Guyton AC, Hall JE, editors. Tratado de Fisiologia Médica. Rio de Janeiro: Guanabara Koogan; 1999. p. 735-750 
7. Lee WM, Diaz-Espineira M, Mol JA, Rynberk A, Kooistra HS. Primary hypothyroidism in dog is associated with elevated GH release. J Endocrionol 168:59-66, 2001

8. Feldman EC, Nelson RW. The thyroid gland. In: Feldman EC, Nelson RW, editors Canine and Feline Endocrinology and Reproduction. Philadelphia: Elsevier Science: 2004. p. 86-249

9. Eghbali M, Deva R, Alioua A, et al. Molecular and functional signature of heart hypertrophy during pregnancy. Circ Res 96:1208-1216, 2005

10. Blanco PG, Batista PR, Re NE, et al. Eletrocardiographic changes in normal and abnormal canine pregnancy. Reprod Domest Anim 47:252-256, 2012

11. Darvelid AW, Linde-Forsberg C. Dystocia in the bitch: a retrospective study of 182 cases. J Small Anim Pract 35:402-407, 1994

12. Tilley LP. Essentials of Canine and Feline Eletrocardiography: interprelation and treatment. 3th ed Philadelphia: Lea \& Febiger; 1992

13. Münnich A, Küchenmeister U. Dystocia in numbers-evidence-based parameters for intervention in the dog: causes for dystocia and treatment recommendations. Reprod Domest Anim 44:141-147, 2009

14. Linde-Forsberg C, Persson G. A survey of dystocia in the Boxer breed. Acta Vet Scand 49:1-9, 2007

15. McLean L. Single pup syndrome in an English Bulldog: failure of luteolysis Companion Anim 17:17-20, 2012

16. Gabas DT, Oliva VNLS, Matsuba SHV. Estudo clínico e cardiorrespiratório em cadelas gestantes com parto normal ou submetidas à cesariana sob anestesia inalatória com sevofluorano. Arq Bras Med Vet Zootec 58:518-524, 2006

17. Abbott JA. The effect of pregnancy on echocardiographic variables in healthy bitches. J Vet Cardiol 12:123-128, 2010

18. Blanco PG, Tórtora M, Rodríguez R, Arias DO, Gobello C. Ultrasonographic assessment of maternal cardiac function and peripheral circulation during normal gestation in dogs. Vet J 190:154-159, 2011

19. Kienle RD. The effects of systemic disease on the cardiovascular system. In: Kittelson MD, Kienle RD, editors. Small Animal Cardioascular Medicine Textbook. St. Louis: Mosby; 1998. p. 552-560

20. Fantoni DT, Cortopassi SRG, Bernardi MM. Anestésicos intravenosos e outros parenterais. In: Spinosa HS, Górniak SL, Bernardi MM, editors. Farmacologia Aplicada à Medicina Veterinária. Rio de Janeiro: Guanabara Koogan; 1996. p. 104-114

21. Fillipi LH. O Eletrocardiograma na Medicina Veterinária. São Paulo: Roca; 2011

22. Lucio CF: Canine neonatal vitality and biochemistry profile under distinct obstetric conditions. Dissertation [Master in Animal Reproduction]. São Paulo: Faculty of Veterinary Medicine and Animal Science; 2008, p. 1-76.
23. Miller MS, Tilley LP, Smith Jr FWK, Fox PR. Eletrocardiography. In: Fox PR, Sisson DD Moise NS, editors. Textbook of Canine and Feline Cardiology: Principles and Clinical Practice. 2nd ed. Philadelphia: Saunders; 1999. p. 67-105

24. Condrea M. Aspects regarding gestation anemia at the bitch. Lucrări Stiintifice Medicină Veterinară 17:221-223, 2009

25. Chaudhari SUR, Mshelia GD. Evaluation of the haematologic-values of bitches in Northern Nigeria of the stating of pregnancy. Pak J Biol Sci 9:310-312, 2006

26. Gonçalves LC, Silva MRG, Peraçoli JC. Prevalência de hipertensão arterial em mulheres com passado de distúrbios hiperglicêmicos na gestação. Arq Bras Endocrinol 49:265-270, 2005

27. Al-Bassam MA, Thomson RG, O'Donnell L. Involution abnormilites in postpartum uterus of bitch. Vet Pathol 18:208-218, 1981

28. Macintire DK, Drobatz KJ, Haskins SC, Saxon WD. Manual of Small Animal Emergency and Critical Care Medicine. 2nd ed Oxford: Willey-Blackwell; 2013

29. Gaido SR: A gestação e a anestesia. In: Proceedings of 3rd Encontro de Anestesiologia Veterinária. Araçatuba: Colégio Brasileiro de Cirurgia e Anestesiologia Veterinária; 1997.

30. Martin PA, Crump MH. The adrenal gland. In: Pineda MH, Dooley MP, editors. McDonald's Veterinary Endocrinology and Reproduction. Ames: Iowa State Press; 2003. p. $165-200$

31. Bergstrom A, Fransson B, Lagersteott A-S, Kindahl H, Olsson U, Olsson K. Hormonal concentrations in bitch primary uterine inertia. Theriogenology 73:1068-1075, 2010

32. Davidson AP. Primary uterine inertia in four labrador bitches. J Am Anim Hospital Assoc 47:83-88, http://dx.doi.org/10.5326/JAAHA-MS-5122

33. Soldin PO, Tractenberg RE, Soldin SJ. Differences between measurements of the $\mathrm{T}_{4}$ and $\mathrm{T}_{3}$ in pregnant and nonpregnant women using isotope dilution tandem mass spectrometry and immunoassay: are there clinical implications? Clin Chim Acta 347:61-69, 2004

34. Mestman JH, Goodwin TM, Montoro MM. Thyroid disorders in pregnancy. Endocr Clin North Am 24:42-71, 1995

35. Scott-Moncrieff CJ: Clinical Signs and Concurrent Diseases of Hypothyroidism in Dogs and Cats. Department of Veterinary Clinical Sciences, School of Veterinary Medicine, Purdue University, VCS/LYNN, 625 Harrison Street, West Lafayette, IN 47907-2026, USA.

36. Cavalieri RR. The effects of nonthyroid disease and drugs on thyroid function tests. Med Clin N Am 75:27-39, 1991 